\title{
Using new technologies to deliver test results in primary care: structured interview study of patients' views
}

\author{
James Grayston ${ }^{1}$, Karen Fairhurst ${ }^{2}$ and Brian McKinstry ${ }^{3}$ \\ ${ }^{1}$ Medical Student, Centre for Population Health Sciences: General Practice Section, University of Edinburgh, \\ Edinburgh, UK \\ ${ }^{2}$ Senior Lecturer, Centre for Population Health Sciences: General Practice Section, University of Edinburgh, \\ Edinburgh, UK \\ ${ }^{3}$ Reader, Centre for Population Health Sciences: General Practice Section, University of Edinburgh, Edinburgh, UK
}

\begin{abstract}
Background: An increasing number of blood tests are being performed in primary care. Informing patients of results takes up a considerable proportion of practice-staff time. The use of new technologies may be more time-efficient for staff but little is known about the acceptability to patients. Objective: To determine patient attitudes towards the use of three technologies - short message service (SMS), webpage and email - for the delivery of laboratory results. Design: Structured interview. Methods: Two hundred patients were interviewed in two general practices in Lothian, Scotland. Satisfaction with current methods and preferred methods of obtaining test-results were assessed. Patients were asked about their current access to different technologies and their favourability to using such technologies for receiving results and their views on appropriate content and information security. Results were analyzed by age, sex and educational attainment using $\chi^{2}$ test. Results: A total of $79.5 \%$ of patients had mobile phones, $53 \%$ used SMS, $46.5 \%$ had internet, and $37.5 \%$ used e-mail. E-mail, SMS and webpage was the favoured delivery system for $53.3 \%, 37.1 \%$ and $33.3 \%$, respectively. Conclusion: Patients were favourable towards e-mail but not SMS or a webpage. The main concern over the three technologies was information security. New technology may be useful for delivering results but patients will have to be persuaded that any such system is reliable and secure.
\end{abstract}

Key words: e-health; laboratory results; primary care

Received 17 March 2009; accepted 1 November 2009; first published online 10 December 2009

\section{Introduction}

An increasing number of blood tests are being performed in primary care. This is being driven by the increasing prevalence of chronic disease in an aging population (Crimmins, 2004) and incentivisation of chronic disease management in the

Correspondence to: Brian McKinstry, Centre for Population Health Sciences: General Practice Section, University of Edinburgh, $20 \mathrm{~W}$ Richmond St, Edinburgh EH8 9DR, UK. Email: brian.mckinstry@ed.ac.uk
General Medical Services Quality and Outcomes Framework (Department of Health, 2008). It is important that blood test results are provided in a safe and timely manner that is convenient to both patients and health-care staff. The transmission of results to patients is also a potential source of error, so systems used must be reliable and accurate. One possible way of managing this increasing demand is to deliver laboratory results to patients using new technologies such as short message service (SMS) text messaging, internet webpage and e-mail. The asynchronous nature of 
communication using these technologies, in that they allow communication at convenient times for both patients and health care staff, is potentially time efficient and the textual basis of the communication potentially ensures accurate and reliable transmission of information.

New technologies are being used increasingly to deliver health care but their implementation has been piecemeal, and evidence of acceptability mixed. For example, SMS has been utilized to improve outpatient attendance via appointment reminders (Downer et al., 2006; Chen et al., 2008), increase vaccination rates in travellers (Vilella et al., 2004) and reduce anxiety in surgical patients (Huang et al., 2006). Clinically, SMS has been used to optimize the management of asthma (Anhøj and Møldrup, 2004) and diabetes (FerrerRoca et al., 2004) and in sexual health (Lim et al., 2008). However, in one study evaluating preferences for receiving sexual health screening results, few patients expressed a preference for SMS (Brown et al., 2008). A recent study of the use of SMS in routine clinical care in one general practice found that, although it was technically feasible, uptake of the service by patients was modest (Neville et al., 2008). The National Health Service (NHS) in England is currently in the process of introducing electronic health records for all patients - aiming to allow sharing of patients' health records between different parts of the NHS. Patients will also have access to their summary care records via the HealthSpace website (Connecting for Health, 2004). It is planned for the summary care record to include discharge records and test results. An online survey connected to the HealthSpace website found that a majority of patients were keen to use the service to track their test results (Connecting for Health, 2004), but it is not clear how representative the response rate was of patients in general. Patients who have access to e-mail have been found to have a high level of interest in using e-mail to communicate with health services (Car and Sheikh, 2004). Neville et al. (2004) reported that patients found an e-mail consultation service helpful in an urban general practice. Studies on the willingness of patients to receive specific test results by e-mail in the United States have found a high favourability towards receiving basic blood test results such as cholesterol and blood sugar levels (Couchman et al., 2001; Couchman et al., 2005).
In this study we aimed to determine

- the current practices of patients with regard to obtaining blood test results and their satisfaction with these methods,

- patient levels of access/usage of new technologies and their favourability to obtaining results by these methods,

- any concerns over confidentiality and information security.

\section{Methods}

Postal surveys in general practice typically have a low response rate (Foy et al., 1998), therefore in order to maximize response rate we interviewed patients actually attending their practice using a semi-structured interview. Two hundred patients were surveyed in two general practices in Lothian, Scotland. One was a city centre practice with a demographically mixed population; one in a relatively deprived small town with a largely White population.

The interview structure and content were developed from existing literature and piloted with a small $(n=15)$ convenience sample. Following piloting small adjustments were made to the schedule.

Patients aged 18 years or older who were attending the nurse or phlebotomist for blood tests, or had an appointment with the doctor were informed of the survey by the receptionist on arrival. To be eligible to be included in the study patients had to be either having a blood test on the day of interview or to have had a blood test in the past. They were asked to participate on leaving their appointment by the interviewer. Interviews lasted for around 5-10 min and were conducted at different times of day in order to reach different demographic groups.

Patients having a blood test that day were asked if the test was regular or a 'one-off' and how they planned to get the result. All patients who had previously had a blood test were asked how they received the result and how satisfied they were with that method. Satisfaction was measured on a 5-point Likert scale ranging from Very Dissatisfied (1) to Very Satisfied (5). They were then asked what their favoured methods of obtaining a result would be. Those who had access to mobile phone, internet and e-mail were asked 
specifically about how favourable they would be to results being made available in that format using a similar Likert scale. Patients were then asked about how much detail messages should contain, what sort of content the message should have and if they had worries over information security and confidentiality. The participants' age, sex and educational background were recorded.

Results were analyzed by age and sex using $\chi^{2}$ tests. For the purpose of analysis patients were split into groups of 'older' and 'younger'. The age of 45 was chosen to make this split as it was near the median of the sample. The 1-5 scale of satisfaction and favourability were dichotomized into not favourable/not satisfied and favourable/satisfied. A sensitivity analysis was subsequently performed attributing those who scored neutrally to favourable/satisfied. Results reported as significant were significant to the $5 \%$ level. For the free response questions, the recorded comments were read and re-read, and a thematic coding frame was developed. Each comment was then examined and coded according to the framework and the number of comments within each theme was counted.

\section{Results}

Two hundred and thirty patients were approached for interview and 200 consented (87\%; 100 from each practice). Thirty patients declined to be interviewed, mostly due to time constraints. The age of participants ranged between 18 and 87, and was distributed as shown in Table 1.

When split into the groups 'older' and 'younger', $67.5 \%$ were in the 'older' age category. There were around twice as many women as men in the sample. This is consistent with general practice attendee populations in Scotland. No qualifications were held by $34.5 \%$ of the sample. School qualifications were held by $33.5 \%$ : Certificate of Secondary Education or equivalent $11.5 \%$, O-level or equivalent $11.5 \%$ and A-level or Scottish Higher $10.5 \%$. Only $9.5 \%$ had degree level education. This is a lower level of educational atainment than that of the general Scottish population (SCROL, 2001).

\section{Access to technology}

The level of access to different technologies in the sample is shown in Table 2. Mobile ownership
Table 1 Age distribution of sample

\begin{tabular}{lcc}
\hline Age group (years) & \multicolumn{2}{c}{ Number of patients } \\
\cline { 2 - 3 } & Male & Female \\
\hline $18-24$ & 2 & 6 \\
$25-34$ & 7 & 14 \\
$35-44$ & 8 & 25 \\
$45-54$ & 13 & 23 \\
$55-64$ & 13 & 22 \\
$65-74$ & 14 & 25 \\
$75+$ & 13 & 15 \\
\hline
\end{tabular}

stood at $79.5 \%$, SMS use at $53 \%$, internet access at $46.5 \%$ and e-mail use at $37.5 \%$.

Significantly more women used SMS text messaging than men $78(60 \%)$ versus 28 (42\%), $P<0.01$. There was no association between sex and mobile ownership, internet access or e-mail use.

\section{Satisfaction with current methods}

Most patients phoned the practice for their results $(n=75,38.3 \%)$, obtained their results face-to-face with the doctor $(n=75,38.3 \%)$, or were phoned by the practice $(n=28,14.3 \%)$. A small number got their result by post $(n=8$, $4.1 \%$ ). Patients showed a high level of satisfaction with the previous method of getting their result, with only $10.3 \%$ being dissatisfied overall.

\section{Preferred methods}

Patients preferred methods of obtaining test results are shown in Figure 1. The most popular individual choice was the patient phoning the practice, accounting for 59 (22.3\%) cases. Alltogether, face-to-face consultations were preferred by 77 (29\%). Methods, which involved talking to a doctor accounted for 79 (29.8\%) responses. Only $11(4.2 \%)$ responses were for the three new technologies being considered in this study. E-mail accounted for eight (3\%) responses while SMS and webpage accounted for two $(0.8 \%)$ and one $(0.4 \%)$, respectively.

\section{SMS}

When asked about their favourability towards getting their blood test result by SMS, $62.9 \%$ of patients who had access $(n=159)$ were unfavourable or neutral. Older patients were significantly 
Table 2 Access to technology

\begin{tabular}{llrrr}
\hline Technology & & \multicolumn{2}{l}{ Number of patients (\%) } \\
\cline { 3 - 5 } & & Older & Younger & Total \\
\hline Mobile phone & Own phone & $97(71.9)$ & $62(95.4)$ & $159(79.5)$ \\
& Do not own phone & $38(28.1)$ & $3(4.6)$ & $31(15.5)$ \\
SMS text & Use SMS & $48(35.6)$ & $58(89.2)$ & $106(53.0)$ \\
& Do not use SMS & $87(64.4)$ & $7(10.8)$ & $94(47.0)$ \\
Internet & Have Internet access & $44(32.6)$ & $49(75.4)$ & $93(46.5)$ \\
& Do not have Internet access & $91(67.4)$ & $16(24.6)$ & $107(53.5)$ \\
E-mail & Use E-mail & $32(23.7)$ & $43(66.2)$ & $75(37.5)$ \\
& Do not use E-mail & $103(72.3)$ & $22(33.8)$ & $125(62.5)$ \\
\hline
\end{tabular}

$\mathrm{SMS}=$ short message service.

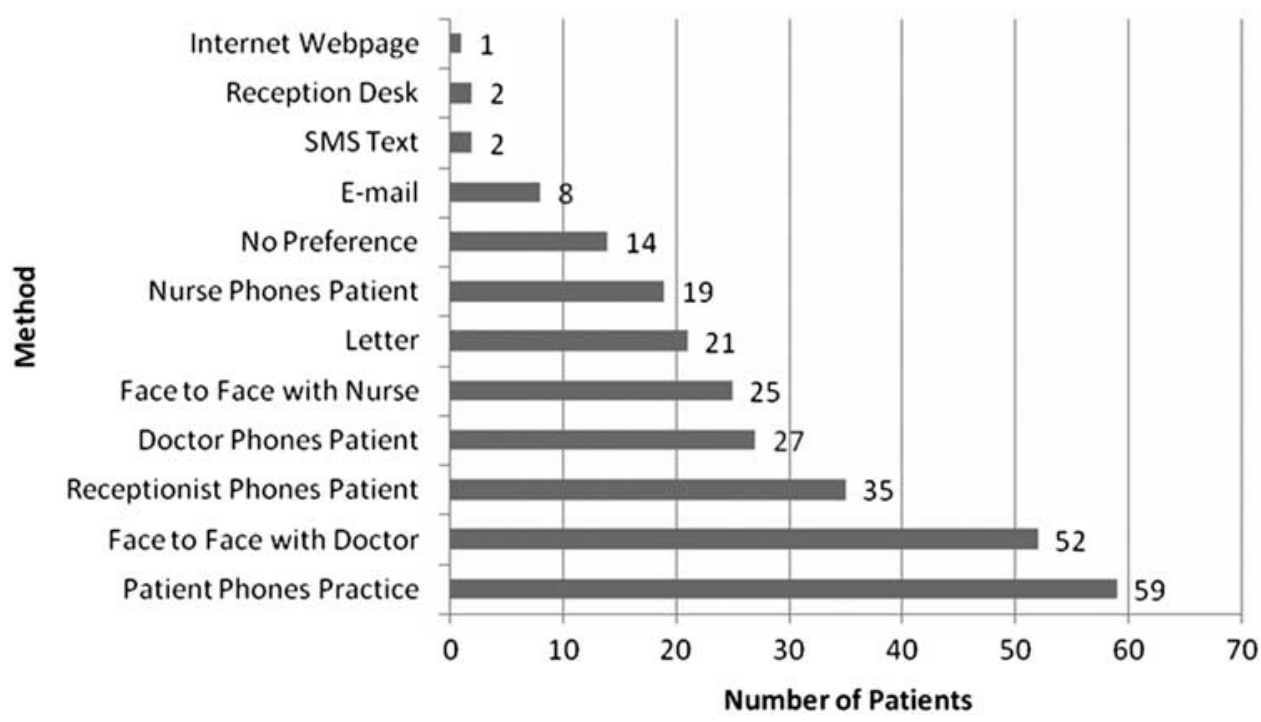

Figure 1 Preferred methods of obtaining test results

more unfavourable than younger patients 71 $(73.2 \%)$ versus $29(46.8 \%), P<0.01$. There was no association between sex and favourability towards SMS text message. The reasons that patients who had access $(n=159)$ gave for being favourable or unfavourable towards SMS are shown in Table 3. The most common reasons for being favourable towards SMS were it is quick and efficient $(34.6 \%)$, and convenient $(17 \%)$. The most common concerns were about information security and confidentiality of SMS $(21.3 \%)$, SMS being impersonal $(18.2 \%)$ and not being confident to use SMS (19.5\%).

\section{Webpage}

The favourability towards receiving results on an internet webpage of those who had access $(n=93)$ was similar to that of SMS text, $66.7 \%$ being unfavourable or neutral. Female patients were significantly more unfavourable towards the use of an internet webpage than male patients 45 $(77.6 \%)$ versus $17(48.6 \%)(P<0.01)$. There was no association between age and favourability towards an internet webpage. The reasons that patients who had access $(n=93)$ gave for being favourable or unfavourable towards a website are shown in Table 4. The most common reasons 
Table 3 Comments about SMS

\begin{tabular}{lll}
\hline Comment & $\begin{array}{l}\text { Number of } \\
\text { patients }\end{array}$ & $\begin{array}{l}\text { Percentage of those } \\
\text { with access (\%) }\end{array}$ \\
\hline Information security and confidentiality concerns & 34 & 21.3 \\
Would not be confident using SMS & 31 & 19.5 \\
SMS is impersonal & 29 & 18.2 \\
SMS is unreliable & 11 & 6.9 \\
A bad result could cause panic & 10 & 6.2 \\
You could not ask questions & 7 & 4.4 \\
'Happy as it is' & 7 & 4.4 \\
SMS text messages are too short & 6 & 3.8 \\
SMS text should be used on an informal basis only & 6 & 3.8 \\
The message would be open to misinterpretation & 5 & 3.1 \\
The message could be deleted by accident & 3 & 1.9 \\
Would be quick and efficient & 55 & 34.6 \\
Would be convenient & 27 & 17 \\
Would not forget to get result & 10 & 6.2 \\
Could get results anywhere & 4 & 2.5 \\
Message would be a permanent reference & 2 & 1.3 \\
Would save money & 2 & 1.3 \\
\hline
\end{tabular}

$\mathrm{SMS}=$ short message service

Table 4 Comments about a website

\begin{tabular}{lcc}
\hline Comment & $\begin{array}{l}\text { Number of } \\
\text { patients }\end{array}$ & $\begin{array}{l}\text { Percentage of those } \\
\text { with access (\%) }\end{array}$ \\
\hline Security concerns & 36 & 38.7 \\
$\quad$ A secure site could be hacked & 9 & 9.7 \\
$\quad$ Anybody could see your results & 16 & 17.2 \\
Would be impersonal & 10 & 10.8 \\
Do not use the internet often & 7 & 7.5 \\
Would not be confident using the internet & 6 & 6.5 \\
Worries over reliability & 27 & 29 \\
Easy access and convenience & 19 & 20.4 \\
Would be quick and save time & 8 & 8.6 \\
More information could be included than in a SMS text & 5 & 5.3 \\
Could be linked to other resources (eg, appointments) & 3 & 3.2 \\
Would save paper and be environmentally friendly & 2 & 2.1 \\
You would have control of when to access it & & \\
\hline
\end{tabular}

SMS $=$ short message service.

for being favourable towards an internet webpage were it would be quick and save time $(20.4 \%)$ and provide access and convenience $(29 \%)$. The most common concerns were about information security and confidentiality of SMS (48.4\%), and the webpage being impersonal $(17.2 \%)$.

\section{E-mail}

Of those who had access to e-mail $(n=75), 53.3 \%$ were favourable to receiving laboratory results in that format. Neither age nor sex showed a significant relationship with favourability towards e-mail.

The reasons that patients who had access $(n=75)$ gave for being favourable or unfavourable towards e-mail are shown in Table 5. The most common reasons for being favourable towards e-mail were it is quick and efficient $(44.0 \%)$, and convenient $(30.7 \%)$. The most common concerns were again about information security and confidentiality of e-mail (33.3\%), and e-mail being impersonal $(16.0 \%)$. 
Table 5 Comments about e-mail

\begin{tabular}{lll}
\hline & Number of & $\begin{array}{l}\text { Percentage of those } \\
\text { with access (\%) }\end{array}$ \\
\hline Womment & 33 & 44 \\
Easy access and convenience & 23 & 30.7 \\
E-mail is more personal than the internet & 4 & 5.3 \\
Would be able to get results anywhere & 3 & 4 \\
Could hold more information than a SMS text & 3 & 4 \\
Would be a permanent reference & 3 & 4 \\
Would be environmentally friendly & 3 & 4 \\
Could reply with questions & 3 & 4 \\
Could be printed out for records & 2 & 2.7 \\
Would be in control on whether to read e-mail & 2 & 2.7 \\
Information security and confidentiality concerns & 25 & 33.3 \\
E-mail is impersonal & 12 & 16 \\
E-mail is unreliable & 6 & 8 \\
Do not check e-mail often & 3 & 4 \\
Would not be confident using e-mail & 2 & 2.7 \\
Could delete the message by accident & 2 & 2.7 \\
\hline
\end{tabular}

\section{Sensitivity analysis}

For the purpose of analysis neutral results were counted as not favourable. However, if neutral were to be counted as favourable overall then participants would have been $52 \%$ favourable towards SMS text, and older people were significantly more unfavourable towards the internet. Otherwise no other results would have changed significantly.

\section{Preferences for content}

With regard to the content of the messages most respondents only wanted to know if the result was 'OK or not' and what they needed to do next. Alltogether, $45.2 \%$ wanted the actual result to be included in the message. Younger patients were significantly less likely to want the actual result than older patients $22(35.5 \%)$ versus 49 (51.6\%), $P<0.05$. However, this may reflect the larger proportion of older patients having warfarin monitoring.

Those who were having warfarin monitoring wanted to know their international normalized ratio, the dose of warfarin they should take, and the date of their next appointment.

Some saw a webpage and e-mail as giving the opportunity for more detailed explanation of the results. It was also suggested that a webpage could give links to further information and even be linked to other resources such as an online appointments system.

\section{Information security}

Concerns about information security were most frequently cited as a disadvantage of all three technologies.

Older patients were significantly less concerned over the security of SMS text messaging than younger patients $28(28.9 \%)$ versus $27(43.5 \%)$ $(P<0.05)$. There was no association between age and concerns over e-mail or web security.

Women were significantly more concerned over the security of a webpage than men $45(78.9 \%)$ versus $19(54.3 \%) \quad(P<0.05)$. There was no association between gender and information security concerns with SMS or e-mail.

\section{Discussion}

\section{Strengths and limitations}

The study had a very high participation rate $(87 \%)$ and represented typical adult general practice attendee populations in age and sex. However, the study was conducted in only two practices and so caution must be exercised in generalizing from this data.

\section{Results}

This study shows that, in general, patients are very satisfied with the system that they currently use to obtain results, a finding consistent with 
existing evidence that patients tend to like what they know (Porter and MacIntyre, 1984). Although this finding may genuinely reflect good current service provision, it does not exclude the possibility that use of new technologies could improve patient experience. Patients, however, will clearly have to be persuaded of the benefits of any new system being implemented - using new technology or not - before they take it up.

Patients preferred to obtain results either faceto-face or by telephone calls from a clinician echoing research in preferences for delivery of sexual health results (Brown et al., 2008). Indeed one of the biggest concerns about the three technologies was that they seemed impersonal. This reservation could potentially be tempered by attributing authorship of messages to a specific clinician.

The main concern over the use of all three technologies was information security; particularly in relation to web-based results, which they perceived could be easily 'hacked' and that text messages to mobile phones could be seen by others. Although it remained an important concern a significantly smaller proportion of patients were concerned about the security of e-mail compared to a website. It is not clear whether concerns over information security are due to personal experience or extensive coverage of such problems in the media. It is clear, however, that if any of these systems were to be implemented patient concerns about the security of the system would have to be addressed and allayed.

Older people had reduced access to all the technologies in this study. Mobile phone ownership among older people was fairly high, but use of SMS was much lower. Internet access and e-mail usage was also less common among older people in this study in keeping with findings in the general population (Baker et al., 2003). These low levels of technology use in the group most accessing routine tests could severely limit the scope of any of these systems. While the level of mobile phone ownership suggests SMS text might have most future potential it was the most disliked possible medium for obtaining results. Implementation of one of these systems may therefore have to be a compromise between patient perceptions and coverage of the technology.

In terms of content, most patients only wanted to know whether their results were 'OK or not' and what they needed to do next, but SMS was criticized for being too short and lacking the ability to ask questions. E-mail was compared favourably to SMS, a few patients commenting that it could hold more information. Some saw the possibility of being able to reply to the e-mail with questions. It was also noted that a webpage could hold more information than an SMS text and could be linked to other services. This will be the situation as the HealthSpace website is developed in England (Connecting for Health, 2004).

E-mail was the only one of the three technologies that patients were favourable towards overall. This confirmed American research that patients with access to e-mail are keen to use it to communicate with health services (Couchman et al., 2001). This may be a reflection of the selected population who use e-mail. They account for the smallest group of patients and are likely to be the most 'computer literate'. As has been found in studies (Couchman et al., 2005) of e-mail for the delivery of test results, speed, efficiency and convenience were the most commonly considered advantages of all three technologies.

Technologies such as e-mail and text messaging may also be used to make results more accessible to those with speech or hearing impairment (Power et al., 2007).

\section{Areas for further study}

A trial and evaluation of the implementation of one or more of these systems in a general practice setting would help to further elucidate their acceptability and the validity of the concerns expressed. The intervention should include attempts to allay information security concerns from the outset, and be as straightforward to use and personal as possible. The evaluation should address which system works best, for which patients and in what context.

\section{Conclusions}

This study has found that patients were generally happy with the way they currently received their results, and had concerns about receiving them by SMS or via web page. Among those that had access to email just over half would like to receive results in that medium. There were major concerns about information security with every technology. 
Current limited access to new technology by older people will limit the scope of these systems. Patients will have to be persuaded that any new technology for delivering results is efficient, reliable and secure.

\section{Acknowledgements}

The authors thank to Dr Margaret McDougal for her advice on the design of the interview. Brian McKinstry is supported by a fellowship from the Chief Scientist Office of the University of Edinburgh Ethical approval was obtained from the SSC4 ethics committee of the University of Edinburgh.

\section{References}

Anhøj, J. and Møldrup, C. 2004: Feasibility of collecting diary data from asthma patients through mobile phones and SMS (short message service): response rate analysis and focus group evaluation from a pilot study. Journal of Medical Internet Research 6, e42.

Baker, L., Wagner, T.H., Singer, S. and Bundorf, M.K. 2003: Use of the Internet and e-mail for health care information: results from a national survey. Journal of the American Medical Association 289, 2400-406.

Brown, L., Copas, A., Stephenson, J., Gilleran, G. and Ross, J.D. 2008: Preferred options for receiving sexual health screening results: a Population and Patient Survey. International Journal of STD \& AIDS 19, 184-87.

Car, J. and Sheikh, A. 2004: E-mail consultations in health care: 2 - acceptability and safe application. British Medical Journal 329, 439-42.

Chen, Z.W., Fang, L.Z., Chen, L.Y. and Dai, H.L. 2008: Comparison of an SMS text messaging and phone reminder to improve attendance at a health promotion center: a randomized controlled trial. Journal of Zhejiang University. Science. B. 9, 34-38.

Connecting for Health. 2004: Connecting Americans to Their Healthcare. Final Report of the Working Group on Policies for Electronic Information Sharing Between Doctors and Patients. New York, USA: Markle Foundation.

Couchman, G.R., Forjuoh, S.N. and Rascoe, T.G. 2001: E-mail communications in family practice: what do patients expect? Journal of Family Practice 50, 414-18.

Couchman, G.R., Forjuoh, S.N., Rascoe, T.G., Reis, M.D., Koehler, B. and Walsum, K.L. 2005: E-mail communications in primary care: what are patients' expectations for specific test results? International Journal of Medical Informatics 74, 21-30.

Crimmins, E.M. 2004: Trends in the health of the elderly. Annual Review of Public Health 25, 79-98.

Department of Health. 2008: Quality and Outcomes Framework (QOF): Retrieved 29 May 2008 from http:// www.dh.gov.uk/en/Healthcare/Primarycare/Primarycare contracting/QOF/index.htm

Downer, S.R., Meara, J.G., Da Costa, A.C. and Sethuraman, K. 2006: SMS text messaging improves outpatient attendance. Australian health review 30, 389-96.

Ferrer-Roca, O., Cárdenas, A., Diaz-Cardama, A. and Pulido, P. 2004: Mobile phone text messaging in the management of diabetes. Journal of Telemedicine and Telecare 10, 282-85.

Foy, R., Parry, J. and McAvoy, B. 1998: Clinical trials in primary care: targeted payments for trials might help improve recruitment and quality. British Medical Journal 317, 1168-69.

Huang, F., Liu, S.C., Shih, S.M., Tao, Y.H., Wu, J.Y., Jeng, S.Y. and Chang, P. 2006: Reducing the anxiety of surgical patient's families access short message service. AMIA Annual Symposium Proceedings 957.

Lim, M.S., Hocking, J.S., Hellard, M.E. and Aitken, C.K. 2008: SMS STI: a review of the uses of mobile phone text messaging in sexual health. International Journal of STD \& AIDS 19, 287-90.

Neville, R.G., Marsden, W., McCowan, C., Pagliari, C., Mullen, H. and Fannin, A. 2004: E-mail consultations in general practice. Informatics in Primary Care 12, 207-14.

Neville, R.G., Reed, C., Boswell, B., Sergeant, P., Sullivan, T. and Sullivan, F.M. 2008: Early experiences of the use of short message service (SMS) technology in routine clinical care. Informatics in Primary Care 16, 203-11.

Porter, M. and MacIntyre, S. 1984: What is, must be best: a research note on conservative or deferential responses to antenatal care provision. Social Science \& Medicine 11, 1197-200.

Power, M.R., Power, D. and Horstmanshof, L. 2007: Deaf people communicating via SMS, TTY, relay service, fax, and computers in Australia. Journal of Deaf Studies and Deaf Education 12, 80-92.

Scotland's Census Results Online (SCROL). 2001. Education Profile for Scotland. Retrieved 29 May 2008 from http:// www.scrol.gov.uk

Vilella, A., Bayas, J.M., Diaz, M.T., Guinovart, C., Diez, C., Simo?, D., Muñoz, A. and Cerezo, J. 2004: The role of mobile phones in improving vaccination rates in travelers. Preventive Medicine 38, 503-509. 


\section{Appendix}

\section{Structured Interview}

\section{The Current Test}

Is this a regular test or a one-off? Regular/One-off

How had you planned to get the result of this test?

Face to Face

Practice Phones Patient

Patient Phones Practice

Letter
Other

Other...

$$
\text { Practice Phones Patient }
$$

\section{Letter}

How satisfied were you with this method?

Very Dissatisfied

1
Dissatisfied 2

Neutral
3

Satisfied

4
Very Satisfied

5

\section{General Attitudes}

Ideally, what would be your preferred method of receiving the result of your test?

$$
\begin{aligned}
& \text { Face to Face - Doctor } \\
& \text { Face to Face - Nurse } \\
& \text { Doctor Phones Patient }
\end{aligned}
$$$$
\text { Nurse Phones Patient }
$$

Receptionist Phones

Patient

Patient Phones Practice

SMS Text Message

Internet Webpage
E-mail

Other...... 


\section{Access to Technology}

Do you own a mobile phone? $\mathrm{Y} / \mathrm{N}$

Do you use SMS text messaging? $\quad \mathrm{Y} / \mathrm{N}$

Do you have access to the internet? $\mathrm{Y} / \mathrm{N}$

Do you use e-mail? $\quad \mathrm{Y} / \mathrm{N}$

\section{SMS Text Messaging}

\section{General}

How favourable would you be towards receiving the result of this test by SMS text message?

$\begin{array}{ccccc}\text { Very Unfavourable } & \text { Unfavourable } & \text { Neutral } & \text { Favourable } & \text { Very Favourable } \\ 1 & 2 & 3 & 4 & 5 \\ \text { What are the reasons for this response? } & & & \end{array}$

Are there any situations in which you think you wouldn't wish to receive your result by SMS text? $\mathrm{Y} / \mathrm{N}$

What are they?

\section{Content of the Message}

What information would you like to be included in such a message?

Would you like the specific result (i.e. the number) to be included? $\mathrm{Y} / \mathrm{N}$ Security and Confidentiality

Do you have any concerns over the security or confidentially of results delivered by SMS text messaging? $\mathrm{Y} / \mathrm{N}$

What are they?

How could these be handled? 
152 James Grayston, Karen Fairhurst and Brian McKinstry

Would you worry that the result might not reach you? $\mathrm{Y} / \mathrm{N}$

Free Response Questions

What do you see as the main advantages to the delivery of results by SMS text message?

What do you consider the main disadvantages the delivery of results by SMS text message?

\section{Internet Webpage}

\section{General}

How favourable would you be towards receiving the result of this test on an internet webpage?

$\begin{array}{ccccc}\text { Very Unfavourable } & \text { Unfavourable } & \text { Neutral } & \text { Favourable } & \text { Very Favourable } \\ 1 & 2 & 3 & 4 & 5 \\ \text { What are the reasons for this response? } & & \end{array}$

Are there any situations in which you think you wouldn't wish to receive your result over the internet? $\mathrm{Y} / \mathrm{N}$

What are they?

\section{Content of the Message}

What information would you like to be included on the webpage?

\section{Security and Confidentiality}

Do you have any concerns over the security or confidentially of results given on the internet? $\mathrm{Y} / \mathrm{N}$ What are they?

How could these be handled? 
Free Response Questions

What do you see as the main advantages to the delivery of results over the internet?

What do you consider the main disadvantages the delivery of results over the internet?

\section{E-Mail}

\section{General}

How favourable would you be towards receiving the result of this test by e-mail?

$\begin{array}{ccccc}\text { Very Unfavourable } & \text { Unfavourable } & \text { Neutral } & \text { Favourable } & \text { Very Favourable } \\ 1 & 2 & 3 & 4 & 5\end{array}$

What are the reasons for this response?

Are there any situations in which you think you wouldn't wish to receive your result by e-mail?

$$
\mathrm{Y} / \mathrm{N}
$$

What are they?

\section{Content of the Message}

What information would you like to be included in the e-mail?

\section{Security and Confidentiality}

Do you have any concerns over the security or confidentially of results delivered by e-mail? $\mathrm{Y} / \mathrm{N}$

What are they?

How could these be handled? 
154 James Grayston, Karen Fairhurst and Brian McKinstry

Would you worry that the result might not reach you? $\mathrm{Y} / \mathrm{N}$

Free Response Questions

What do you see as the main advantages to the delivery of results by e-mail?

What do you consider the main disadvantages the delivery of results by e-mail?

\section{Demographic}

Sex $M / F$

Postcode.

Age on completion of full time education

Age.

Currently in

Education...................................
Highest Level of Qualification Obtained

Postgraduate Degree

First Degree

Higher Education Below Degree

A Level or Equivalent

O Level or Equivalent

CSE or equivalent

Foreign or Other

No Qualification

Refused 